\title{
Mapping landslide susceptibility from small datasets: A case study in the Pays de Herve (E Belgium)
}

\author{
Alain Demoulin $^{\mathrm{a}, \mathrm{b}, *}$, Chang-Jo F. Chung ${ }^{\mathrm{c}}$ \\ ${ }^{a}$ Department of Physical Geography and Quaternary, University of Liège, Sart Tilman, B11, B-4000, Liège, Belgium \\ b National Fund for Scientific Research, Belgium \\ c Spatial Data Analysis Laboratory, Geological Survey of Canada, Ottawa, Canada
}

Received 11 July 2006; received in revised form 21 December 2006; accepted 9 January 2007

Available online 19 January 2007

\begin{abstract}
A landslide susceptibility map is proposed for the Pays de Herve (E Belgium), where large landslides affect Cretaceous clay outcrop areas. Based on a Bayesian approach, this GIS-supported probabilistic map identifies the areas most susceptible to deep landslides. The database is comprised of the source areas of ten pre-existing landslides (i.e. a sample of 154 grid cells) and of six environmental data layers, namely lithology, proximity to active faults, slope angle and aspect, elevation and distance to the nearest valley-floor. A 30-m-resolution DEM from the Belgian National Geographical Institute is used for the analysis. Owing to the small size of the sample, a special cross-validation procedure of the susceptibility map is performed, which uses in an iterative way each of the landslides to test the predictive power of the map derived from the other landslides. Four different sets of variables are used to produce four susceptibility maps, whose prediction curves are compared. While the prediction rates associated with the models not involving the "proximity to active fault" criterion are comparable to those of the models considering this variable, strong weaknesses inherent in the fault data on which the latter rely suggest that the final susceptibility map should be based on a model that excludes any reference to fault. This highlights the difference between a triggering factor and determining factors, and in the same time broadens the scope of the produced map. A single reactivated slide is also used to test the possibility of predicting future reactivation of existing landslides in the area. Finally, the need for geomorphological control over the mathematical treatment is underlined in order to obtain realistic prediction maps.
\end{abstract}

(C) 2007 Elsevier B.V. All rights reserved.

Keywords: Landslide hazard; Landslide prediction; Susceptibility map; W Europe

\section{Introduction}

In the last three decades, an abundant literature has been concerned with landslide hazard prediction, using the concepts of hazard and prediction in many different

\footnotetext{
* Corresponding author. Department of Physical Geography and Quaternary, University of Liège, Sart Tilman, B11, B-4000, Liège, Belgium. Tel.: +32 4 3665660; fax: +3243665722 .

E-mail address: ademoulin@ulg.ac.be (A. Demoulin).
}

senses. This has given rise to innumerable, more or less meaningful landslide hazard zonation and prediction maps (Guzzetti et al., 1999). The definition of hazard includes several aspects, among which temporal and spatial probabilities as well as the "intensity" (or magnitude) of landsliding are most important (Varnes, 1984; Flageollet, 1999). However, as suggested by Einstein (1997) and reflected in the USGS procedure where slope stability maps are a distinct part of the hazard zonation maps (USGS, 1982/83), it is preferable to separate the 
spatial and temporal probability estimates. The former are related to the particular combinations of "determining" factors favourable to landsliding, whereas the latter depend on probability of occurrence of the timedependent triggering factors (Leroi, 1997) such as earthquakes or heavy precipitations.

There are several ways, from purely qualitative to quantitative, to produce predictive maps that portray the spatial distribution of landslide hazard (Guzzetti et al., 1999; Clerici et al., 2002; Chung and Fabbri, 2004). However, they all rely on the basic assumption that "slope failures in the future will be more likely to occur under the conditions which led to past and present instability" (Guzzetti et al., 1999, Chung and Fabbri, in press). Mainly based on field geomorphological evidence, some maps are either simple inventories of past events (Highland, 1997; Soldati, 1999), often developed in isopleth maps (Wright et al., 1974; DeGraff, 1985; Guzzetti et al., 1994), or are direct geomorphological maps of landslide-prone areas whose quality strongly depends on the investigator's ability to identify potential slope failures (Humbert, 1977; Dumas et al., 1984; Kienholz et al., 1984; Zimmerman et al., 1986). In order to overcome partly the problem of subjectivity inherent in geomorphological mapping, semi-quantitative hazard maps use a more systematic frame where spatial units of varying nature (catchment and slope unit) are ranked into classes of relative landslide susceptibility on the basis of their environmental characteristics (Hutchinson and Chandler, 1991; Siddle et al., 1991; Moon et al., 1992; Fell et al., 1996) and where GIS and statistical analysis may already be invoked (Carrara et al., 1977, 1991; Irigaray et al., 1999). Such a statistics-oriented approach finally leads to fully quantitative maps that locate future landslide occurrence as a result of a GIS-based multivariate statistical analysis (Rezig et al., 1996; Leroi, 1997). Provided a validation of the results is carried out, these are objective and meaningful tools for landslide hazard prediction (Chung et al., 1995; Chung and Fabbri, 2004, in press).

While a main drawback of the heuristic approach is its subjective character, it will also happen that a purely mathematical GIS-based treatment of environmental variables could be misleading and yield unrealistic hazard maps. Indeed, the benefit of covering uniformly and objectively a study area can be counteracted by an inadequate choice of the predictor variables or by the errors associated with data manipulation (Guzzetti et al., 1999). When predicting landslide hazard, a careful balancing of the geomorphologist's expertise in the field and the objectivity of mathematical analysis is thus highly desirable. The two methods are complementary and this paper aims to demonstrate how to take advan- tage of their combination, where a GIS-based probabilistic treatment is supported by geomorphological field considerations. Not only will a geomorphological evaluation be given of the mathematically obtained landslide susceptibility map, but also field evidence will be used to check input data and probabilities. Our main purpose is, however, to explore the possibility of building a susceptibility map in an area where few landslides have occurred, and especially of validating it. We stress again that, while we try to predict the spatial distribution of future landslide occurrences, varying causes (earthquake, climate and human influence) may be involved in their production, which renders temporal estimates of landslide probability all the more unrealistic, as some of these causes may change over time.

\section{Geomorphological, geological and climatic setting}

Several ancient large landslides have recently been described to the east of Liège, in eastern Belgium (Demoulin et al., 2003) (Figs. 1 and 2). Radiocarbon dating suggests that some of them could have appeared around $150 \mathrm{AD}$. Reactivation episodes have also been identified around 400, 700 and $1300 \mathrm{AD}$, and at least two landslides are presently active. A number of new houses were recently built close to, and even on slipped terrains, two of them being damaged during a reactivation event in 1998 (Demoulin and Glade, 2005). This obviously makes sufficient land-planning justification for analysing the landslide hazard in the area. Furthermore, while it is highly difficult to estimate a return period for natural reactivations of old landslides, several observations show that any human intervention on or close to disturbed slopes can also cause catastrophic ground displacement (Graulich, 1969).

The study area belongs to the Pays de Herve, a moderately dissected tableland. Its mean altitude is $250 \mathrm{~m}$, with a relief of $80-100 \mathrm{~m}$ and slope angles that rarely exceed $12^{\circ}$. The ancient landslides occupy a total area of $0.9 \mathrm{~km}^{2}$ and are all located in the central part of the main $\mathrm{E}-\mathrm{W}$ running divide, separating the Meuse and Vesdre basins, and on a secondary S-striking divide (Figs. 1 and 3). Most of the landslides started in the upper part of moderate $\left(4-10^{\circ}\right)$ slopes. They are generally compound (multiple rotational + translational) landslides, up to $700 \mathrm{~m}$ in width and $400 \mathrm{~m}$ in length, and show steep arcuate head scarps, up to $17 \mathrm{~m}$ high.

The geology of the Pays de Herve is characterized by the extensive preservation of subhorizontal Cretaceous cover deposits resting on a folded Paleozoic basement. Whilst the shales of the basement crop out in the valleys, the Upper Cretaceous cover forms the bulk of the ridges 


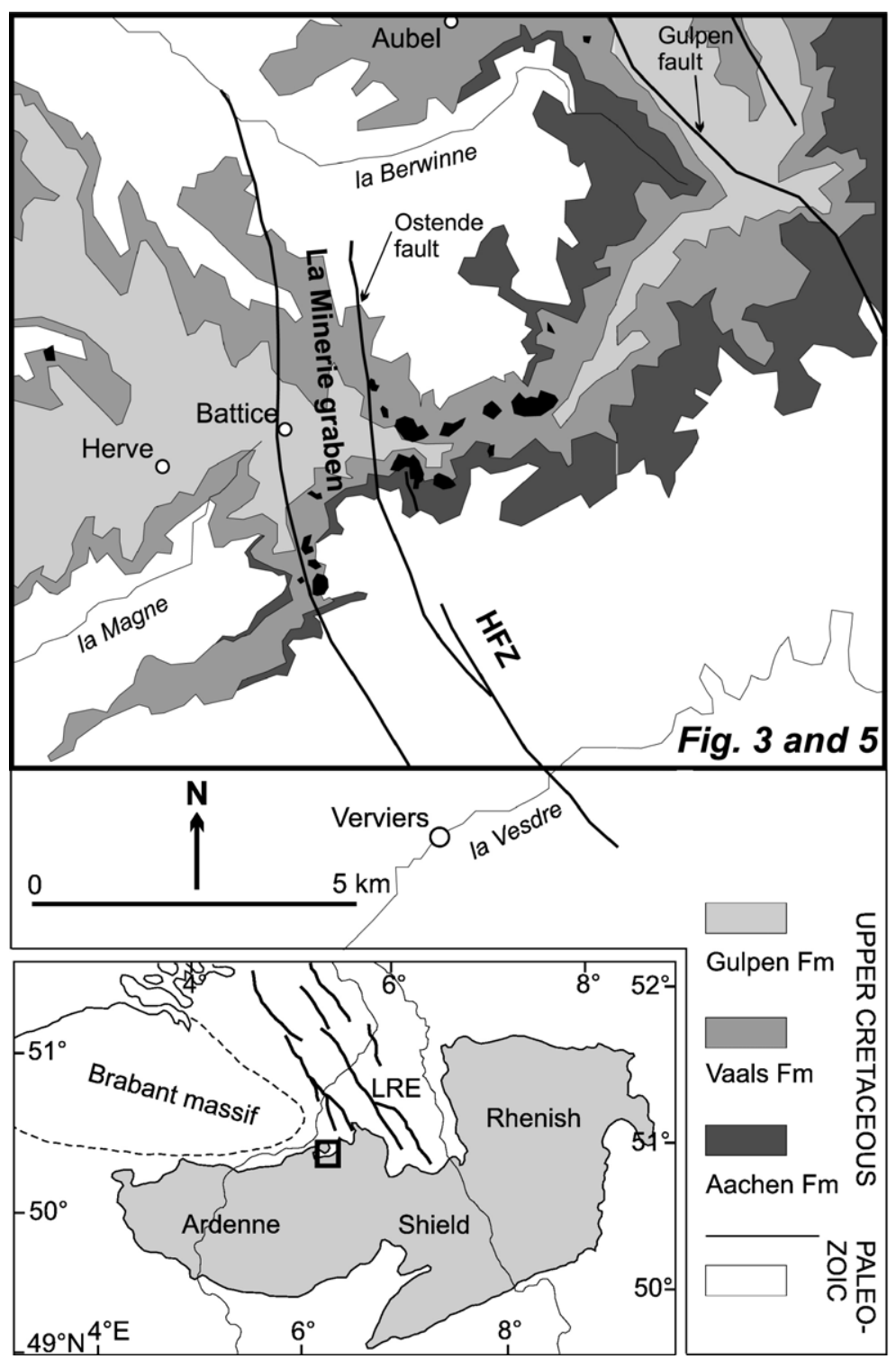

Fig. 1. Simplified geological map of the study area and location of the landslides. The landslides are represented in black. HFZ: Hockai fault zone. The inset locates the study area with respect to the Rhenish shield and the Lower Rhine Embayment (LRE).

(Fig. 1). At its base, the Aachen Formation is mainly composed of fine sands interlayered with coarse sands and clays. In the study area, the Aachen sands may be up to $10 \mathrm{~m}$ thick. The overlying Vaals Formation displays glauconiferous clays and marls. Its maximum thickness is $25 \mathrm{~m}$ in the area affected by landslides. To the east, it gradually becomes sandier, with some indurated layers. Resting on the Vaals clays, the chalks of the Gulpen Formation are well preserved on top of most ridges of the Pays de Herve. In their upper metres, they are generally weathered to clay-with-flints and can no longer be distinguished from the weathered Maastricht chalks. They display large solution pockets filled with Oligocene sands and Quaternary loess.

With regard to hydrology, the main aquifer of the Pays de Herve lies within the Gulpen chalks, but numerous small aquifers may also exist within the Aachen sands, trapped between the clays resulting from the Mesozoic weathering of the Paleozoic basement and the Vaals clays. Moreover, a fissure aquifer is to be found locally within the fractured Paleozoic shales. Tectonically, all large landslides of the Pays de Herve are located within or very close to the La Minerie graben (Fig. 1). This small NNW-striking graben is limited by 


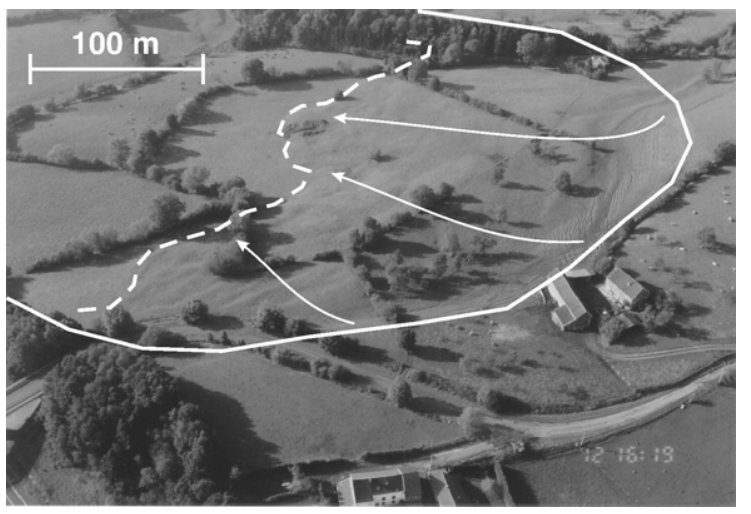

Fig. 2. Oblique aerial view of a typical landslide of the Pays de Herve (number 6 in Fig. 3). The bold line follows the top of the headscarp and the dashed line defines the approximate extent of the landslide.

active faults, namely the Ostende fault segment of the seismogenic Hockai fault zone. An earthquake of estimated $\mathrm{M}_{\mathrm{w}}>6$ is suspected to have occurred in the area in 1692 (Camelbeeck et al., 1999).

All landslides extend mainly in the Vaals clays, but with a basal shear surface systematically starting at the level of the underlying Aachen sands. Demoulin et al. (2003) showed that landsliding was initiated by earthquake-triggered liquefaction of some layers in the
Aachen sands, which first induced the translational gliding of the lower part of the slope, which in turn caused retrogressive rotational sliding in the upper part of the slope. The combined presence of the Aachen sands and the overlying Vaals clays was thus necessary for these landslides to occur.

As for the climatic context, the centennial daily rainfall is $110 \mathrm{~mm}$, without any significant spatial variation within the study area. In 1998, a daily rainfall of $126 \mathrm{~mm}$ caused only a limited reactivation of two preexisting landslides. However, these values cannot be extrapolated to the time of initiation of the large landslides (150 AD?). As the climatic influence is here a temporal much more than a spatial variable, it will not be included in the hazard analysis.

\section{Methodology}

\subsection{Basic idea of the quantitative model}

We assume that the study area is divided with respect to the occurrence of landslides into two non-overlapping sub-areas, respectively the "hazard" (denoted by $\mathbf{M}$ ) and "non-hazard" (denoted by $\overline{\mathbf{M}}$ ) sub-areas. Consider a pixel (or grid cell) $x$ for which the $m$ predictor variables (contained in $m$ GIS thematic and continuous layers)

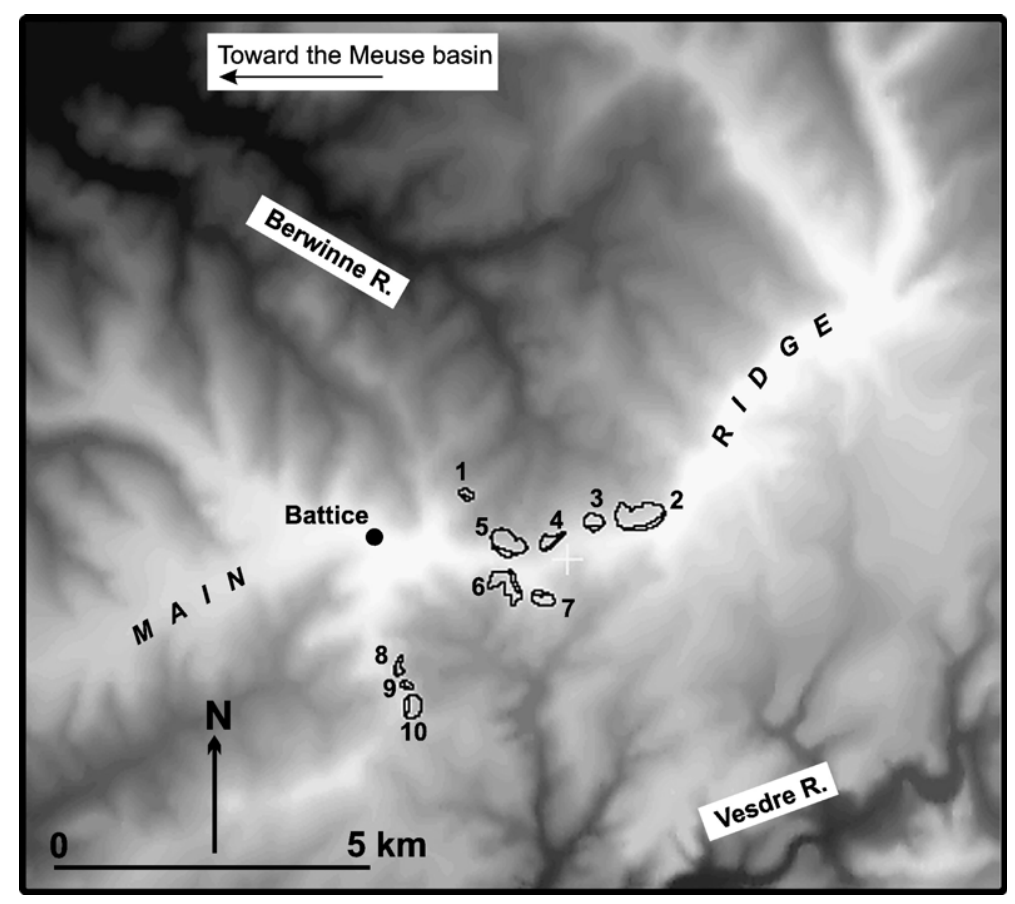

Fig. 3. Digital elevation model of the study area showing the location of the ten landslide scars used in the prediction analysis. The highest elevations are in white. 
take the respective values $x_{1}, \cdots, x_{k}, y_{1}, \cdots, y_{h}$, where the first $k$ values, $x_{1}, \cdots, x_{k}$ correspond to GIS thematic data layers and the subsequent $h$ values, $y_{1}, \cdots, y_{h}$ represent continuous data layers and $m=k+h$. The multivariate likelihood ratio function that the pixel $x$ will belong to the trigger area of a future landslide is denoted by:

$$
\begin{aligned}
& \boldsymbol{\lambda}\left(x: x_{1}, \cdots, x_{k}, y_{1}, \cdots, y_{h}\right) \\
& =\frac{\boldsymbol{f}\left\{x_{1}, \cdots, x_{k}, y_{1}, \cdots, y_{h} \mid \mathbf{M}\right\}}{\boldsymbol{f}\left\{x_{1}, \cdots, x_{k}, y_{1}, \cdots, y_{h} \mid \overline{\mathbf{M}}\right\}}
\end{aligned}
$$

where $\boldsymbol{f}\left\{x_{1}, \cdots, x_{k}, y_{1}, \cdots, y_{h} \mid \mathbf{M}\right\}$ and $\boldsymbol{f}\left\{x_{1}, \cdots, x_{k}, y_{1}\right.$, $\left.\cdots, y_{h} \mid \overline{\mathbf{M}}\right\}$ are read from the multivariate frequency distribution functions in $\mathbf{M}$, and $\overline{\mathbf{M}}$, respectively.

Assuming that the $m$ predictor variables are conditionally independent, we get

$$
\begin{aligned}
& \boldsymbol{\lambda}\left(x: x_{1}, \cdots, x_{k}, y_{1}, \cdots, y_{h}\right)=\boldsymbol{\lambda}\left(x: x_{1}\right) \cdots \boldsymbol{\lambda}\left(x: x_{k}\right) \\
& \quad \times \boldsymbol{\lambda}\left(x: y_{1}\right) \cdots \boldsymbol{\lambda}\left(x: y_{h}\right)
\end{aligned}
$$

where the likelihood ratio functions $\boldsymbol{\lambda}\left(x: x_{i}\right)$ and $\boldsymbol{\lambda}\left(x: y_{j}\right)$ in Eq. (2) are related with the unknown future landslides and cannot be obtained without an assumption on the future landslides. These unknown functions are estimated by substituting the values derived from a set of past landslides for the future landslides and the estimates are obtained by:

$$
\begin{aligned}
& \hat{\boldsymbol{\lambda}}\left(x: x_{1}, \cdots, x_{k}, y_{1}, \cdots, y_{h}\right)=\hat{\boldsymbol{\lambda}}\left(x: x_{1}\right) \cdots \hat{\boldsymbol{\lambda}}\left(x: x_{k}\right) \\
& \quad \times \hat{\boldsymbol{\lambda}}\left(x: y_{1}\right) \cdots \hat{\boldsymbol{\lambda}}\left(x: y_{h}\right)
\end{aligned}
$$

where

$$
\begin{aligned}
\hat{\lambda} & \left(x: x_{1}\right) \\
& =\frac{\# \text { of past landslide pixels in } x_{i} \text { category of the } i \text { th layer }}{\# \text { of non-landslide pixels in } x_{i} \text { category of the } i \text { th layer }}, \text { and }
\end{aligned}
$$$$
\hat{\boldsymbol{\lambda}}\left(x: y_{j}\right)=\frac{\hat{\boldsymbol{f}}\left\{y_{j} \mid \mathbf{M}\right\}}{\hat{\boldsymbol{f}}\left\{y_{j} \mid \overline{\mathbf{M}}\right\}},
$$

with $\hat{\boldsymbol{f}}\left\{y_{j} \mid \mathbf{M}\right\}$ and $\hat{\boldsymbol{f}}\left\{y_{j} \mid \overline{\mathbf{M}}\right\}$ being the empirical frequency distribution functions of the $j$-th continuous data layer in $\mathbf{M}$ and $\overline{\mathbf{M}}$ respectively. As an example, two empirical distribution functions of the single slope angle data layer in two separate subareas, $\mathbf{M}$, the "trigger areas" of the ten landslides contained in the sample and $\overline{\mathbf{M}}$, the remainder of the study area, are illustrated in Fig. 4a. The two functions are distinctly different and hence the corresponding likelihood ratio function of the slope angle (Fig. 4b) should provide a significant contribution to the prediction of landslide hazard in the area.
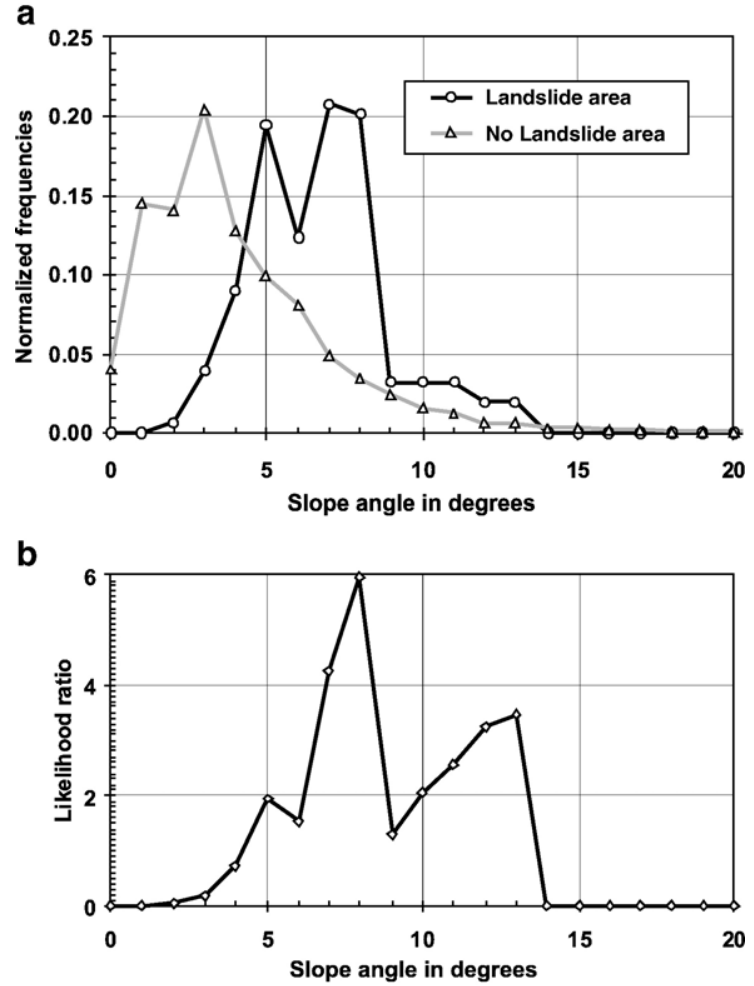

Fig. 4. Example of the likelihood ration function calculated for the "slope angle" independent variable. (a) Empirical distribution functions of the variable in two separate subareas, the "trigger areas" of the ten landslides included in the sample and the remainder of the study area. (b) The corresponding likelihood ratio function (Eq. (4)) of slope angles.

For the likelihood ratio function of Eq. (1), the Bayesian estimator of Eq. (3) is one of the simplest estimators presented in Chung and Fabbri (2004). Beyond easy calculation, this Bayesian approach offers the advantage of yielding significant results already with small datasets. The estimated likelihood ratio function of Eq. (1) cannot be directly interpreted as the actual probability that the pixel will be a part of the trigger area of a future landslide without several specific assumptions on the future landslides. Instead, in the absence of any time dimension, the estimator of Eq. (3) can be used to describe the relative hazard attached to the pixel.

Therefore, rather than the values of the estimator of Eq. (3), we used their ranking to generate a susceptibility map. We sorted all these probabilities (one at each pixel of the study area) in decreasing order (the pixel with the largest estimator is given the highest order) and we replaced each pixel's estimated probability by its rank divided by the total number of pixels. The obtained value was termed "favourability index". The index value 
of the pixel with the largest estimated probability, the predicted most hazardous pixel, is thus 1 , and the pixel with the smallest estimate has the value 1 / total number of pixels.

\subsection{Cross-validation process}

To evaluate the prediction results, we employed the following three-step procedure (Chung and Fabbri, 2004).

Step 1 We remove one landslide from the dataset as if it had not yet occurred.

Step 2 Using the remaining landslides, we construct a prediction model based on the estimator of Eq. (3).

Step 3 To evaluate the prediction efficiency, we appraise the favourability indices obtained in the trigger area of the landslide selected in Step 1 (not used in Step 2). The median index of the test landslide represents its "individual (spatial) prediction rate", indicating how many percents of the ranked pixels (i.e., of the study area) have to be retained in order to include $50 \%$ of this landslide in the hazardous area.

This three-step procedure is repeated for each landslide of the dataset. The prediction rates generated in Step 3 are then combined in the same manner to validate the results of the general prediction (Table 1). Without this kind of cross-validation technique or tests with independent data, susceptibility maps cannot be evaluated and therefore would be meaningless. It also allows us to compare models and to study the contribution of each input layer or of their combination to the prediction models. Such a prediction rate is fundamentally different from the usually reported success rates which only verify that the landslides of the dataset are located within the most hazardous zones of the map identified by the landslides themselves.

\section{Input database for the quantitative analysis}

The study area covers $177.7 \mathrm{~km}^{2}$ and consists of $197,400(=420 \times 470)$ grid cells with a $30 \mathrm{~m}$ resolution. The spatial database consists of seven layers (variables). They are (1) the spatial distribution of the scars of 10 large landslides (with two subsets respectively comprised of the trigger areas and the deposition areas, from which only the former are involved in the analysis); one categorical, qualitative variable: (2) lithology (12 classes); and five quantitative, continuous variables: (3) distance from active faults; (4) distance from drainage network; (5) slope aspect; (6) elevation; and (7) slope angle. The relevance of the independent variables as predictors may be tested by comparing their empirical distribution functions in two separate subareas, respectively the trigger areas of the landslides included in the dataset and the remainder of the study area (Fig. 4).

For each layer, one data value is assigned to each pixel. Whenever we refer to a "future landslide" in this paper, we assume that it pertains to the same landslide population

Table 1

Results of the prediction model a (see caption of Fig. 5)

\begin{tabular}{|c|c|c|c|c|c|}
\hline \multicolumn{3}{|c|}{ A. Cross-validation results } & \multicolumn{3}{|l|}{ B. Model results } \\
\hline $\begin{array}{l}\text { Test landslide number } \\
\text { (Fig. 3) }\end{array}$ & Individual ranking & $\frac{S_{\text {indiv. landsl. }}}{S_{\text {tot. landsl. }}}$ & $\begin{array}{l}\text { Fraction of study area } \\
\text { hazardous }\end{array}$ & $\begin{array}{l}\text { Increasing prediction } \\
\text { rate }\end{array}$ & $\begin{array}{l}\text { Landslide number } \\
\text { (Fig. 3) }\end{array}$ \\
\hline 1 & 0.933 & 0.071 & 0.002 & 0.253 & 2 \\
\hline 2 & 0.998 & 0.253 & 0.013 & 0.286 & 3 \\
\hline 3 & 0.987 & 0.033 & 0.016 & 0.448 & 7 \\
\hline 4 & 0.974 & 0.078 & 0.026 & 0.526 & 4 \\
\hline 5 & 0.971 & 0.091 & 0.027 & 0.610 & 10 \\
\hline 6 & 0.915 & 0.136 & 0.028 & 0.656 & 8 \\
\hline 7 & 0.984 & 0.162 & 0.029 & 0.747 & 5 \\
\hline 8 & 0.972 & 0.045 & 0.067 & 0.818 & 1 \\
\hline 9 & 0.895 & 0.046 & 0.085 & 0.955 & 6 \\
\hline 10 & 0.973 & 0.084 & 0.105 & 1.000 & 9 \\
\hline
\end{tabular}

A. Results of the cross-validation procedure. The individual ranking values correspond to the median favourability indices (ranked from 1 to 0 ) of each landslide successively taken as the test landslide for the validation. $S_{\text {indiv. landsl }} / S_{\text {tot. landsl. }}$ denotes the fraction of $\mathbf{M}$ (summed trigger areas of the ten landslides contained in the dataset) corresponding to each test landslide. B. Prediction rate curve associated with the model and displayed in Fig. 6 , directly derived from the values of the cross-validation. The fraction of the study area to be taken as hazardous in order to get a particular prediction rate equals one minus the ranking (or favourability index) of the related landslide. 
from which the 10 ancient landslides of the dataset had originated. This implies that we predict only landslides similar in characteristics and size to the 10 pre-existing landslides.

\subsection{Landslide scars}

The inventory of landslides has been carried out through the analysis of aerial photographs at 1:10,000 (1947) to 1:18,500 (1971) scale. All landslides identified on the photos have been verified in the field. The 17 confirmed forms have been classified into two types according to morphological expression and size. The first type corresponds to extended deep compound block slides with a steep head scarp, parallel ridges determined by the upper edge of rotated blocks, and a downslope hummocky topography generally terminated by a $2-3 \mathrm{~m}$ high scarplet. Ten landslides, with an average size of 7.8 ha, belong to this first group and are used for the analysis (Fig. 3). Another class collects all small $(<2$ ha), shallow or questionable forms which are not considered for the prediction.

Furthermore, in order to detect the right combination of landslide-favouring variables, we distinguished between the upper zones where the landslides started and the lower zones of deposition. This was done automatically by assigning to the upper "trigger" zone the $15 \%$ of the pixels with highest elevations for each landslide. The scars of the 10 large landslides cover 843 pixels. The selected trigger areas consist of 154 pixels, actually more than $15 \%$ due to the distribution of pixel elevations in each landslide.

\subsection{Morphological data}

Morphological variables have been obtained from a DEM produced by the Belgian National Geographical Institute (IGN) with a resolution of $30 \mathrm{~m}$. This DEM was built by scanning, vectorising and identifying the contour lines of the IGN topographic maps at 1:50,000 scale. For this part of Belgium, the accuracy of elevation data is expected to be $7.8 \mathrm{~m}$. Our experience of comparison with GPS data however suggests that semisystematic errors can vitiate the contour lines of the topographic maps by vertically stretching some valleys, sometimes by much more than $10 \mathrm{~m}$. Fortunately, this especially affects slopes steeper than $20^{\circ}$, which are almost absent from the study area, and one may reasonably expect that the uncertainty on slope values does not exceed $1^{\circ}$. Three morphological variables (elevation, slope angle and slope aspect) have been computed to make as many thematic GIS layers.

\subsection{Geological data}

The geological data come from the new Belgian geological maps at 1:25,000 scale, and are expressed in two GIS layers, one devoted to the bedrock lithology, the other to active faults. Twelve lithological classes have been distinguished. The outcrop areas of two of them ("Devonian and lower Carboniferous" and "Tertiary marine sands and Quaternary deposits") were excluded from the analysis because we know that these rocks are unfit to support the type of landslide we are trying to predict here. Upper Carboniferous shales, Cretaceous Aachen sands and Gulpen chalks and present-day alluvial plain deposits make four further classes. Finally, as all recorded large landslides occurred in outcrop areas of the Vaals clays but in a close causal relationship with the presence of the Aachen sands, we divided the Vaals clays into three subclasses on the basis of proximity to the Aachen sands: $<300 \mathrm{~m}$, between 300 and $500 \mathrm{~m}$, and $>500 \mathrm{~m}$ distance to the outcropping Aachen sands. Since most hillslopes along the potentially threatened ridges are comprised within a narrow range of slope angles and the different rock types correspond to superposed horizontal layers, the proximity (in the $x-y$ plane) of the Vaals clays to the Aachen sands basically represents the depth at which the liquefactionprone sands are encountered below the clays in a particular place. The limit distances were chosen according to the corresponding depth of the top of the sands $(300 \mathrm{~m}$ distance $\approx 30 \mathrm{~m}$ depth) and, secondarily, to the characteristics of the landslide distribution in the area. Moreover, to allow for a possible role of the overlying chalk cover in the landslide distribution, we divided once more the three Vaals subclasses in two subunits depending on the proximity to the Gulpen chalks $(<500 \mathrm{~m}$ and $\geq 500 \mathrm{~m}$ apart from Gulpen outcrops). We thus conducted two parallel analyses using either three subclasses of the Vaals clays (assuming exclusive Aachen sands co-influence) or six Vaals subclasses (with additional influence of the Gulpen chalks) in order to get indications on the landslide mechanism itself through the comparison of the obtained prediction rates (see below).

The "distance to active faults" layer has been created in order to take into account the probable seismic origin of the landslides. Detailed investigation carried out by Demoulin et al. (2003) showed that they were most certainly triggered by an earthquake on the NNW-striking Ostende segment of the Hockai fault zone (Fig. 1). It is widely accepted that the main WSW-striking Variscan thrust faults of the area are now inactive (Fourmarier, 1954). On the contrary, although only the Hockai fault zone reveals clear signs of Quaternary activity, each of the numerous NNW-striking normal faults, parallel to the 
border faults of the Lower Rhine rift segment, must be considered potentially active. We therefore retained only these normal faults to assign to every pixel of the study area a value inversely proportional to the distance to the nearest potentially active structure.

\subsection{Hydrological data}

In the absence of groundwater data, and since soil moisture information is more or less useless with respect to deep landslides, we computed a rather indirect hydrological variable. Assuming that proximity of a valley floor and, secondarily, local slope angle of a hillslope element are good indicators of the local groundwater depth (the higher on a hillslope a pixel is located, and the steeper its slope angle, the more chances the groundwater level has to be deep), we combined both variables to define a proxy variable ("distance to the nearest valley floor") which is supposed to reflect roughly the depth of the aquifer or, in inverse relationship, the residence time of percolating water within each pixel before reaching the top of the aquifer. This variable $(D)$ is computed as

$D=D_{\mathrm{s}}^{*} \mathrm{VF}$

With $D_{\mathrm{s}}=$ Euclidean distance to the nearest valley floor axis, and VF (vertical factor) $=1+0.02 S(S=$ local tangent slope gradient). The 0.02 factor has been chosen empirically to get a reasonable balance between distance and slope influences on the variable.

\section{Results}

Though highly probable, the seismic origin of the pre-existing landslides, and thus the role of active faults as triggering factor, cannot be definitely proved (Demoulin et al., 2003). Moreover, one may wonder whether, beyond the need for the combined occurrence of the Aachen sands and the Vaals clays, the presence of an overlying chalk cover had any influence on the spatial distribution of the landslides. We thus were faced with the difficulty of choosing the right variables for the hazard prediction, so that we conducted four analyses with different sets of variables, either taking into account or not the "distance from active fault" data layer, and also considering three or six lithological subclasses within the Vaals clays outcrop area.

Fig. 5 shows the four maps we obtained, that predict the relative hazard associated with each pixel. In each map, the $1 \%$ most hazardous pixels have been distinguished, then slicing of the favourability indices proceeds by $5 \%$ steps towards less hazardous zones, and non-hazardous areas are coloured in blue tones. The prediction curves associated with the different models
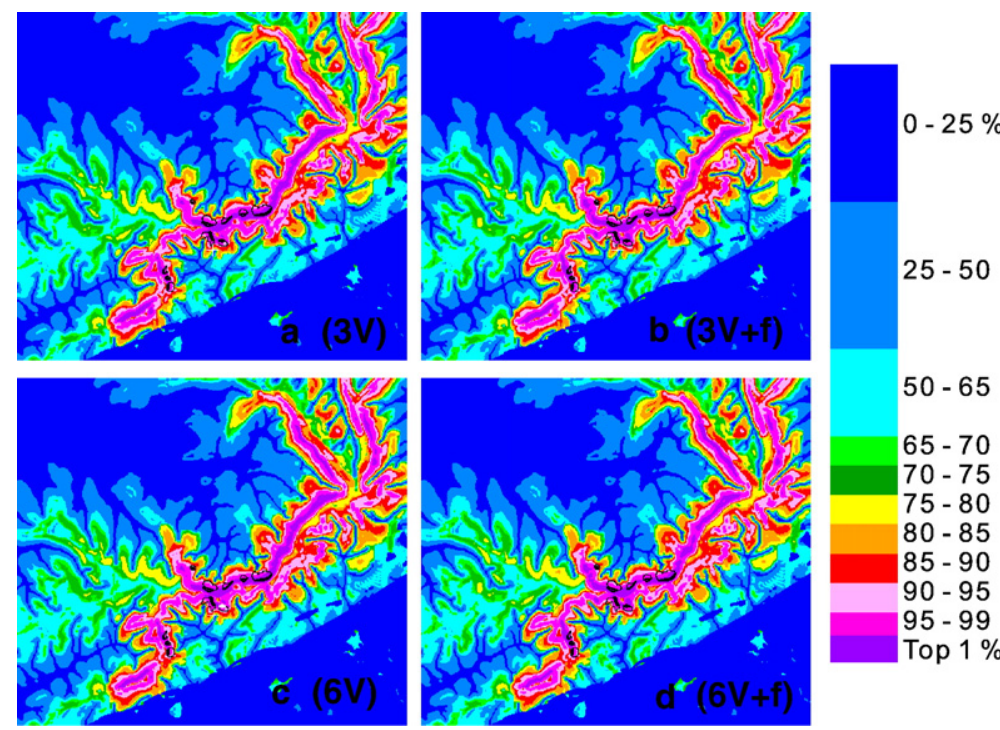

$50-65$

$65-70$

$70-75$

$75-80$

$80-85$

$85-90$

$90-95$

$95-99$

Top $1 \%$

Fig. 5. Relative landslide susceptibility maps, where the pixels are ranked according to their degree of hazard (joint conditional probability). The $1 \%$ most hazardous pixels have been distinguished in violet, then slicing of the favourability indices proceeds by $5 \%$ steps towards less hazardous zones, and non-hazardous areas appearing in blue tones. The landslides are figured in black, with their trigger area delimited by a bold line. (a) Model using five layers of geomorphological information (no "fault proximity") and three lithological subclasses within the Vaals clays outcrop area (see text). (b) Six layers of geomorphological information (with "fault proximity") and three lithological subclasses within the Vaals clays outcrop area. (c) Five layers of geomorphological information (no "fault proximity") and six lithological subclasses within the Vaals clays outcrop area. (d) Six layers of geomorphological information (with "fault proximity") and six lithological subclasses within the Vaals clays outcrop area. 
indicate that, in all cases, the $10 \%$ of pixels with the highest favourability indices suffice to define the areas where every future landslide is expected to occur (Fig. 6). This is indeed an unexpectedly high quality of prediction, probably due to the clear-cut characteristics of the determining environmental variables and to the homogeneity of the database.

The two maps generated without using the "distance from active fault" data layer (Fig. 5a, c) allow a good comparison between the two lithological models (associating or not the chalk cover to the determining environment). They show that the 5\% most hazardous pixels are similarly distributed in both cases, this being still truer at the $1 \%$ level. When we test the influence of the "distance from active fault" variable, we observe a larger discrepancy between the prediction maps (compare either Fig. 5a and b or $\mathrm{c}$ and d). The effect of removing this variable from the analysis is to spread the $1 \%$ most hazardous zone out along the whole length of the main ridge (especially its northern flank, depicting so the influence of the gentle dip to NW of the cretaceous formations). This occurs at the expense of the faulted areas, namely a small NNW-striking ridge located immediately to the west of the main cluster of landslides and aligned with the active Ostende fault, and another ridge of same orientation coinciding with the Gulpen fault line (Fig. 1).

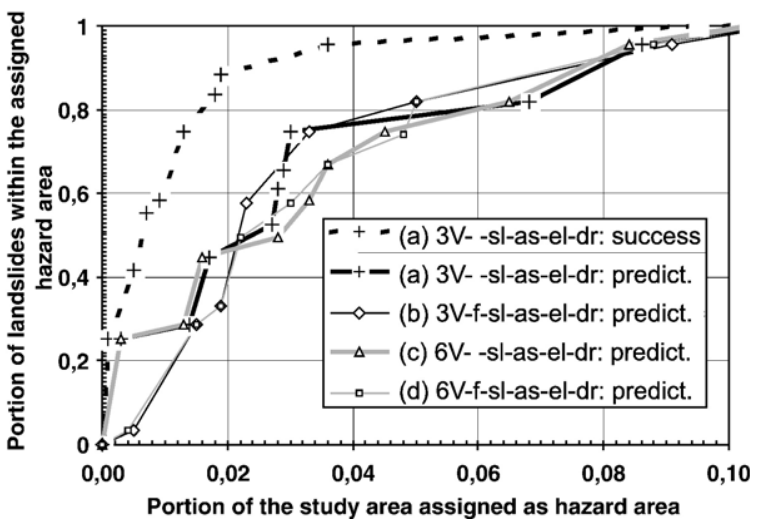

Fig. 6. Prediction rate curves for the four susceptibility maps of Fig. 5 (crosses: model a of Fig. 5; losanges: model b; triangles: model c; squares: model d). These cumulative plots indicate how many "most hazardous" percents of the study area have to be taken into account to predict a given percentage of the future landslides according to each model and the adopted cross-validation process. For the sake of comparison, the success rate curve of model a, indicating how well the landslides used in the prediction are marked as hazardous, is also shown. Letters in the legend box denote the variables used for each model: $6 \mathrm{~V}$ lithology (12 classes - Vaals clay outcrops distributed in six classes); $3 \mathrm{~V}$ - lithology (nine classes - Vaals clay outcrops distributed in three classes); $\mathrm{f}$ - distance from active fault; $\mathrm{sl}$ - slope angle; as — slope aspect; el - elevation; $\mathrm{dr}$ - distance to drainage network.
The respective prediction rate curves express these observations in terms of relative quality of the four tested prediction models (Fig. 6). Although no one of them differs significantly from the others, the best prediction overall is obtained from the simplest model, when the "presence of Gulpen chalk" and "proximity to active fault" factors are not taken into account.

\section{Discussion}

\subsection{Sample size and prediction rate}

In spite of the limited sample size (ten landslides), the Bayesian estimation delivered satisfying prediction rates. Note also that, owing to the cross-validation procedure applied, these rates represent a true prediction, apparently less efficient but much more realistic than the success rates generally provided. Indeed, the success rate evaluates how good the fit is between the predicted hazardous areas and the landslide data used in the prediction process. It is therefore obviously better than a prediction rate (Fig. 6) but, basically, it does not "predict" anything.

Our good results may be explained in two ways. Firstly, each time we validate the model with a single landslide, the latter is composed of 15 pixels on average, which are all tested with their particular set of values of the predictor variables. Thus, the whole cross-validation process actually involved 154 individual pixels, a sample large enough to test the ability of 5-6 variables to identify areas of slope instability. Secondly, the narrow definition of our target, i.e. extended deep landslides requiring very specific, in particular lithological conditions, increases the goodness of prediction. In this respect, the high values of the prediction rates should not be misunderstood. In Fig. 6, on the basis of the sample and the validation of the results, we may safely limit the area subject to this type of landslide to $10 \%$ of the study area, due to the prevailing role of one or two predictors. But assume now that, owing to the improbable occurrence of such landslides in Upper Carboniferous outcrop areas, we have also excluded all these areas from the analysis. Then, we would need to retain a much higher percentage of the remaining pixels to predict the test landslides, therefore apparently getting a worse prediction rate. However, almost exactly the same zones would have been marked as hazardous.

In a landslide susceptibility prediction in $\mathrm{W}$ Belgium, Van den Eeckhaut et al. (2006) used recently a "rare event logistic regression" model to circumvent the problem of small datasets. Although they also concluded that this multivariate model is a useful tool to 
delineate hazard zones, their approach was different from ours in several ways. Firstly, a most commendable feature was the use of reconstructed pre-landslide hillslope gradients instead of the current post-landslide slope angles. Secondly, the logit is the logarithm of the likelihood ratio function shown in our Eq. (1). The logistic model in Van den Eeckhaut et al. (2006) and the estimator used in Eq. (3) here are two different estimation procedures based on two different assumptions (Chung, 2006). In order to interpret the estimate of the logistic model directly as a probability, Van den Eeckhaut et al. (2006) proposed several modifications in the estimation procedure. We do state that a direct probabilistic interpretation of the likelihood ratio function for the occurrences of future landslides is indeed not possible without several specific assumptions on the landslides. In particular, in the absence of any time dimension, the estimates of the likelihood ratio function can only be used to describe the relative level of the probability of occurrence of future landslides. Therefore, the assumed main advantage of a rare event approach, i.e. an improved estimate of the probability of event occurrences, may appear illusory. Thirdly, this approach suffers from subjective choices, e.g. in the selection of data points for the analysis.

\subsection{Meaning of the "proximity of Gulpen outcrops" and "proximity to active fault" parameters and choice of the final prediction map}

At first glance, the spatial distribution of the landslides of the Pays de Herve might seem to be partly dependent on the absence of an overlying chalk cover. However, a closer look at this distribution only revealed a weak relationship, which could not be clearly explained (Demoulin et al., 2003). To cover this uncertainty, we ran two types of models with different lithological map units. The first type considered that only the Aachen sands-Vaals clays combination determined the location of the landslides (Fig. 5a, b) and the second one included the proximity of the chalk outcrops in the determining lithological setting (Fig. 5c,d). Compared pairwise vertically, the prediction maps of Fig. 5 do not display significant differences in the distribution of the most hazardous areas. Likewise, the very similar prediction rate curves obtained for both types of models (Fig. 6) show that the criterion of presence or absence of an overlying chalk cover adds no significant information to the prediction. If the curves are carefully compared, it even appears that taking into account the proximity of chalk outcrops slightly degrades the prediction effectiveness (Fig. 6, middle of the graph). We thus conclude that the proximity of chalk plays no noteworthy role in determining the location of the landslides.

The prediction curves of the hazard models respectively including and ignoring the "active fault" data layer show that removing this layer from the analysis does not change the quality of the prediction (Fig. 6). For instance, in the $3 \mathrm{~V}$-type models, to predict $75 \%$ of the future landslide occurrences requires to retain the $\sim 3.5 \%$ most hazardous pixels of the study area, whether the variable "distance to active fault" is incorporated or not. However, the distribution of the predicted $1 \%$ of most hazardous pixels is slightly different in both cases (Fig. 5a vs. b). In particular, whereas the eastern part of the NE-trending main ridge is identified as a highly hazardous area when no fault data are included in the modelling, in the other case it appears less sensitive than broader zones centred on the faults.

There are several reasons why the prediction map obtained without including the "proximity to active fault" data layer is more meaningful. Firstly, geomorphological and seismological observations show that the Gulpen fault (Fig. 1) and some minor faults included in the database are by no means so active as the Hockai fault zone, close to which all large landslides are located. As far as their trigger role is concerned, it is thus an oversimplification to put all potentially active faults within the same data layer. Strictly, one should weight each fault segment by its estimated seismic activity (e.g., its characteristic earthquake magnitude and return period) in order to eliminate this bias. Unfortunately, in areas of weak to moderate seismicity, this is totally unfeasible, thus leading here to a questionable distribution of the hazardous zones, even though the latter include all existing landslides. Secondly, the landslides in the database probably resulted from a particular combination of seismic and climatic triggers. For instance, assuming a stronger triggering earthquake would require applying broader buffers, thus changing the map units of the "active fault" data layer and the resulting prediction. Another reason why we prefer the susceptibility map without using fault data lies in the long return period of earthquake-triggered landslides (probably in the order of a few kiloyears), which strongly reduces the usefulness of the prediction (see below).

Therefore, the proposed prediction map does not consider the proximity of Gulpen chalk outcrops and uses no fault data. By excluding fault proximity from the factors of landsliding, one reinforces the effectiveness of the search for the characteristic combination of determining environmental variables favourable to this type of landslide, whatever its trigger may be (e.g., 
earthquake, rainfall, human activity, or a combination of them). Fundamentally, this means separating a causal factor of landsliding (the rupturing fault) from landslidefavouring environmental variables. The distinction of triggering and favouring factors actually depicts the difference between the spatial and temporal scales of prediction. Whereas landslide-favouring variables only determine the most probable location of future landslides, triggering factors include also the time dimension. This is by no means in contradiction with the introductory statement that slope failures in the future will be more likely to occur under the conditions which led to past and present instability. It rather emphasizes that, if a particular phenomenon, like deep-seated landslides, may be caused by various triggers, its most effective spatial prediction depends mainly on the distribution of the underlying determining conditions.

Accordingly, keeping the "proximity to active fault" in the set of predictors would mean that it also acts as a determining variable, e.g. through the presence of fault damage zones of intensely fractured rocks, which has been shown not to be the case by the prediction. Therefore, if we nevertheless want to retain the spatial information included in a triggering factor as we do in the models including the "active fault" layer, we restrict the prediction to landslides resulting from this particular cause and the susceptibility map is of narrower application. Conversely, excluding this data layer broadens the scope of the prediction. For instance, from the land-planner's viewpoint, neglecting the fault data layer has the great advantage of better identifying the most sensitive areas whose topographical, hydrological and especially lithological conditions also make any human intervention significantly increase the landslide hazard.

\subsection{Temporal aspect of landslide "probability"}

We already stressed that our prediction map cannot provide any reliable probability of a future landslide occurring in a particular time, due to the extreme looseness of the temporal constraint. If one seeks to estimate an "absolute value" of hazard probability, this could only be done with respect to the database, i.e., in our case, a limited 10 large catastrophic landslides in a period of time of 2000 years or more.

Temporally, the computed predictions apply to a period similar to that covered by the database. This is useless for land-planning purposes, so that, in order to obtain probabilities for a more adequate time interval (50 years for example), we should first make the assumption that they are temporally linear. For earthquake-triggered landslides, this is totally unrealistic at such a timescale, much smaller than the return period of local strong earthquakes. The prerequisite is then to estimate the trigger's frequency (IUGS Working Group on Landslides, Committee on Risk Assessment, 1997), i.e., the recurrence rates of $M>5$ earthquakes on the active fault segments located close to landslide-prone zones in the study area. Not only is this unknown for the major Hockai fault zone (Fig. 1), but also all other potentially active faults would obviously display different recurrence rates for characteristic earthquakes of different sizes. Similarly, in case of a climatic origin of the predicted landslides, the return period of rainfall episodes capable of generating them is all the more difficult to assess, as their threshold amplitude is illdefined and climate oscillations during the last 2000 years also make the precipitation input non-linear. Finally, all probabilities tentatively computed from a set of past landslides are unable to account for the possible superimposed influence of present-day human perturbation of the slopes. Basically, the prediction map cannot therefore be more than a susceptibility map.

\subsection{Predicting reactivation of the existing landslides}

Like in other areas of NW Europe (Dewitte et al., 2006), reactivation of existing landslides is actually the most probable short-term hazard related to landsliding in the Pays de Herve. Indeed, Demoulin et al. (2003) roughly estimated the return period of reactivations at $\sim 400$ years against $>2000$ years for new occurrences of the predicted type of landslide. However, slide reactivation is a phenomenon distinct from the initiation of a new landslide, responding to a broader set of possible causes in a particular environment (i.e. an existing landslide) and at a different spatial scale. The few reactivations known in the Pays de Herve range from 0.1 to 2 ha in size and are about one order of magnitude smaller than the original landslides themselves. As such, they explicitly need separate consideration.

Based on a single observed present-day large reactivation (landslide 10 in Fig. 3), we tentatively explored the possibility of determining which landslides of the study area are most prone to scarp reactivation. The present-day displacements in landslide 10 are mainly triggered by intense rainfall events combined with human-induced permanent high pore pressure (Demoulin and Glade, 2005). Using only determining variables (those involved in the model a presented above) as predictors and leaving any triggering factor out of the modelling, we obtained a ranking of all other landslides assumedly describing their relative susceptibility to reactivation (Table 2). The results basically 
Table 2

Susceptibility to reactivation of the existing landslides of the Pays de Herve

\begin{tabular}{llllllllll}
\hline Landslide (Fig. 3) & 1 & 2 & 3 & 4 & 5 & 6 & 7 & 8 & 9 \\
\hline Ranking & 0.937 & 0.264 & 0.874 & 0.305 & 0.955 & 0.734 & 0.954 & 0.999 & 0.997 \\
\hline
\end{tabular}

The prediction is based on a single reactivated landslide presently observed (landslide 10 in Fig. 3) and uses five independent determining variables (lithology, elevation, slope angle, slope aspect and distance to the nearest drainage axis). The values assigned to the landslides describe their ranking with respect to the whole study area. The closest to 1 a value is, the most reactivation-prone the landslide is predicted. For instance, 0.874 for landslide 3 means that the prediction will hit the landslide (i.e., will describe it as reactivation-prone) provided we consider at least $12.6 \%$ (i.e., $1-0.874$ ) of the study area as hazardous.

show that landslides 8, 9, 5 and 7 (Fig. 3) are characterized by a natural setting most similar to that of the reactivated landslide, which would suggest that they are most prone to reactivation by a similar trigger. This is unsurprising for landslides 8 and 9, located on the same ridge flank, very close to landslide 10 . The fact that landslide 5 was precisely the only other (slightly) reactivated feature in a landsliding event in 1998 and that landslide 7 was reactivated due to highway construction works during the sixties (Graulich, 1969) is more meaningful. But, however good the prediction may appear, such inferences are disputable on several levels. Firstly, the basic assumption that the predicted slope failures should most likely occur under the conditions which led to past instability might be violated, since reactivations and original deep-seated landslides are distinct phenomena possibly determined by different natural conditions. This is true even though we implicitly included a specific variable in the reactivation prediction, namely the need for a pre-existing landslide. Secondly, since the landslide used as input data belongs to the dataset of the original landslides as well as to that of the reactivated features, and the modelling involves in both cases the whole study area and the same predictor variables, there may be a fundamental confusion between reactivation and new occurrences. Thirdly, in the case of reactivation, no validation of the prediction could be carried out. Fourthly, the relative importance of natural and human-induced determining factors in inducing a reactivation is not accounted for by the modelling, and it might as well be that some humaninduced changes would cause reactivation in whatever existing landslide. For instance, the bad ranking of landslide 2 in Table 2 means that the natural conditions to which the determining variables of the model correspond are markedly different between landslides 2 and 10, but it does not rule out that a human-induced change could play an overwhelming determining role and, if applied to landslide 2, make it as unstable as landslide 10 . The point is here that a given trigger (e.g., human-induced high pore pressure) acting in a single place by no means provides information on which threshold values of the determining variables have to be exceeded in order to cause landslide reactivation. Therefore, whereas the prediction identifies the landslides most likely to be reactivated in case of a similar triggering, it remains totally unable to tell that a particular slide is not especially prone to reactivation.

\subsection{Geomorphological control over the statistical treatment}

Beyond their key role in identifying and mapping the landslides, geomorphologists are closely involved in the choice of the variables used for the prediction, namely depending on the type and mechanism of the predicted features. Unfortunately, some limitations of the data set sometimes cannot be overcome. In this study for example, no hydrological field data were available and the proposed proxy only roughly reflects the real hydrological conditions. However, significant results were obtained because the variables most influential on landsliding are related to lithology and geological structure and, in this respect, geomorphology was much more useful than statistics to stress the difficulties arising from the input data in the "active faults" layer.

The geomorphological control is also needed over the mathematical procedure itself. The numeric treatment we carried out prescribes that no map unit of any thematic layer (no category of any thematic variable) can be ascribed a zero probability, even when no slipped pixel is found within it. The consequence is that, although some terrain characteristics make sure that no landslide of the predicted type will occur in the concerned areas, they nevertheless lead to unduly high probabilities of a future slide when associated with other variables more favourable to landsliding. This is the reason why we decided to exclude the outcrop areas of Devonian/lower Carboniferous limestones and sandstones, which are unable to support this type of landslide, from the analysis. Furthermore, if necessary, geomorphologists can take account of the random character of conditional probabilities derived from a limited database by adjusting them following their field 
knowledge, although this introduces subjectivity. In our study, all higher conditional probabilities derived from the database appeared realistic. We thus had no reason for modifying them.

Finally, note that this type of prediction map forecasts the zones most sensitive to failure but does not reveal anything on how the initiated landslides will move downslope and endanger further areas. Although equally relevant to the hazard prediction, this problem has to be tackled by other zonation maps requiring a quite separate procedure.

\section{Conclusion}

The landslide hazard prediction study conducted in $\mathrm{E}$ Belgium has shown that small datasets can yield landslide susceptibility maps of significant predictive power. This results partly from the chosen Bayesian approach but also from the well-defined environmental conditions leading to the predicted type of landslide. The efficiency of the model has been demonstrated by the successful validation of the results through a procedure especially built up for small samples. However, when the predicted features may have different immediate causes, one should carefully avoid including triggering factors among the predictor variables since they restrict the scope of the prediction map and convey often a poorly constrained time dimension. Beyond the sample size, the reliability of the susceptibility map fundamentally depends on a good knowledge of which environmental variables act to determine landsliding and, of course, on the availability and the quality of the data. To be reliable or simply useful, the prediction map must also be appropriately validated.

\section{Acknowledgments}

This research has been financially supported by the Walloon Region through Agreement nr 99/42075. We thank Marc Salmon for having worked out the GIS database. This research is also partially supported by "Reducing Risks from Natural Hazard" Program of the Earth Sciences Sector of Natural Resources Canada. The authors also wish to thank SpatialModels Inc. for allowing the use of its computer program, Spatial Prediction Modeling System, throughout the study.

\section{References}

Camelbeeck, T., Vanneste, K., Alexandre, P., 1999. L'Europe occidentale n'est pas à l'abri d'un grand tremblement de terre. Ciel Terre 115, 13-23.
Carrara, A., Publiese-Caratelli, E., Merenda, L., 1977. Computer based data bank and statistical analysis of slope instability phenomena. Z. Geomorphol. 21, 187-222.

Carrara, A., Cardinali, M., Detti, R., Guzzetti, F., Pasqui, V., Reichenbach, P., 1991. GIS techniques and statistical models in evaluating landslide hazard. Earth Surf. Process. Landf 16, 427-445.

Chung, C.J., 2006. Using likelihood ratio functions for modeling the conditional probability of occurrence of future landslides for risk assessment. Comput. Geosci. 32, 1052-1068.

Chung, C.J., Fabbri, A., 2004. Systematic procedures of landslidehazard mapping for risk assessment using spatial prediction models. In: Glade, T., Anderson, M., Crozier, M. (Eds.), Landslide Hazard and Risk. Wiley, Chichester, pp. 139-174.

Chung, C.J., Fabbri, A., in press. Predicting future landslides for risk analysis - spatial models and cross-validation of their results. Accepted for publication in Geomorphology.

Chung, C.J., Fabbri, A., van Westen, C., 1995. Multivariate regression analysis for landslide hazard zonation. In: Carrara, A., Guzzetti, F. (Eds.), Geographical Information Systems in Assessing Natural Hazards. Kluwer Acad. Publ., Dordrecht, pp. 107-133.

Clerici, A., Perego, S., Tellini, C., Vescovi, P., 2002. A procedure for landslide susceptibility zonation by the conditional analysis method. Geomorphology 48, 349-364.

DeGraff, J., 1985. Using isopleth maps of landslides deposits as a tool in timber sale planning. Bull. Am. Assoc. Eng. Geol. 22, 445-543.

Demoulin, A., Glade, T., 2005. Recent landslide activity in Manaihan, E Belgium. Landslides 1, 305-310.

Demoulin, A., Pissart, A., Schröder, C., 2003. On the origin of late Quaternary palaeolandslides in the Liège (E Belgium) area. Int. J. Earth Sci. (Geol. Rdsch.) 92, 795-805.

Dewitte, O., Chung, C.J., Demoulin, A., 2006. Reactivation hazard mapping for ancient landslides in West Belgium. Nat. Hazards Earth Syst. Sci. 6, 653-662.

Dumas, B., Guéremy, P., Lhenaff, R., Raffy, T., 1984. Mouvements de terrain et risques associés: présentation d'un essai cartographique. Coll. on "Mouvements de terrain". Assoc. Fr. Géogr. Phys., Caen $161-171$.

Einstein, H., 1997. Landslide risk - systematic approaches to assessment and management. In: Cruden, D., Fell, R. (Eds.), Landslide Risk Assessment. Balkema, Rotterdam, pp. 25-50.

Fell, R., Walker, B., Finlay, P., 1996. Estimating the probability of landsliding. Proc. 7th Austr. New Zeal. Conf. on Geomechanics, Adelaide. Institute of Engineers, Australia, Canberra, pp. 304-311.

Flageollet, J.C., 1999. Landslide hazard - a conceptual approach in risk viewpoint. In: Casale, R., Margottini, C. (Eds.), Floods and Landslides: Integrated Risk Assessment. Springer Verlag, Berlin, pp. 3-18.

Fourmarier, P., 1954. La tectonique. Prodrome d'une description géologique de la Belgique. Soc. Géol. Belg., 609-744.

Graulich, J.M., 1969. La géologie de l'autoroute Liège-Aachen entre Herve et La Saute (Clermont). Prof. Pap. Serv. Géol. Belg. 5 (61 pp.).

Guzzetti, F., Cardinali, M., Reichenbach, P., 1994. The AVI project: a bibliographical and archive inventory of landslides and floods in Italy. Environ. Manage. 18, 623-633.

Guzzetti, F., Carrara, A., Cardinali, M., Reichenbach, P., 1999. Landslide hazard evaluation: a review of current techniques and their application in a multi-scale study, Central Italy. Geomorphology 31, 181-216.

Highland, L., 1997. Landslide hazard and risk: current and future directions for the United States Geological Survey's landslide 
program. In: Cruden, D., Fell, R. (Eds.), Landslide Risk Assessment. Balkema, Rotterdam, pp. 207-213.

Humbert, M., 1977. La cartographie ZERMOS. Modalités et établissement des cartes des zones exposées à des risques liés aux mouvements du sol et du sous-sol. Bull. B.R.G.M. section III, $5-8$.

Hutchinson, J., Chandler, M., 1991. A preliminary landslide hazard zonation of the undercliff of the Isle of Wight. In: Chandler, R. (Ed.), Slope Stability Engineering. Developments and Applications. T. Telford, pp. 197-206.

Irigaray, C., Fernandez, T., El Hamdouni, R., Chacon, J., 1999. Verification of landslide susceptibility mapping: a case study. Earth Surf. Process. Landf 24, 537-544.

IUGS Working Group on Landslides, Committee on Risk Assessment, 1997. Quantitative risk assessment for slopes and landslides - the state of the art. In: Cruden, D., Fell, R. (Eds.), Landslide Risk Assessment. Balkema, Rotterdam, pp. 3-12.

Kienholz, H., Schneider, G., Bichsel, M., Grunder, M., Mool, P., 1984. Mapping of mountain hazards and slope stability. Mount. Res. Dev. 4, 247-266.

Leroi, E., 1997. Landslide risk mapping: problems, limitations and developments. In: Cruden, D., Fell, R. (Eds.), Landslide Risk Assessment. Balkema, Rotterdam, pp. 239-250.

Moon, A., Olds, R., Wilson, R., Burman, B., 1992. Debris flow zoning at Montrose, Victoria. Proc. 6th Intern. Symp. on Landslides, vol. 2. Balkema, Rotterdam, pp. 1015-1022.
Rezig, S., Favre, J., Leroi, E., 1996. The probabilistic evaluation on landslide risk. Proc. 7th Intern. Symp. on Landslides, vol. 1. Balkema, Rotterdam, pp. 351-356.

Siddle, H., Jones, D., Payne, H., 1991. Development of a methodology for landslip potential mapping in the Rhondda Valley. In: Chandler, R. (Ed.), Slope Stability Engineering. Developments and Applications. T. Telford, pp. 137-148.

Soldati, M., 1999. Landslide hazard investigations in the Dolomites (Italy): the case study of Cortina d'Ampezzo. In: Casale, R., Margottini, C. (Eds.), Floods and Landslides: Integrated Risk Assessment. Springer Verlag, Berlin, pp. 281-294.

USGS, 1982/83. Goals and tasks of the landslide part of a groundfailure hazards reduction program. Geol. Surv. Circ. 880, 1-48.

Van den Eeckhaut, M., Vanwalleghem, T., Poesen, J., Govers, G., Verstraeten, G., Vandekerckhove, L., 2006. Prediction of landslide susceptibility using rare events logistic regression: a case study in the Flemish Ardennes (Belgium). Geomorphology 76, 392-410.

Varnes, D., 1984. Landslide hazard zonation; a review of principles and practice. Commission of Landslide of IAEG, UNESCO. Natural Hazades, vol. 3. Paris, 63 pp.

Wright, R., Campbell, R., Nilsen, T., 1974. Preparation and use of isopleth maps of landslide deposits. Geology 2, 483-485.

Zimmerman, M., Bichsel, M., Kienholz, H., 1986. Mountain hazards mapping in the Khumbu Himal, Nepal, with prototype map, scale 1:50,000. Mount. Res. Dev. 6, 29-40. 